\title{
Applications of iron oxide nano composite in waste water treatment-dye decolourisation and anti- microbial activity
}

\begin{abstract}
Nano particles have a great potential to be used in waste water treatment. Its unique characteristic of having high surface area can be used efficiently for removing toxic metal ions, microbes, organic dyes from water. Iron oxide nano particles have many biomedical applications. The iron oxide nano composite was synthesised by co precipitation method. Activated charcoal was coated on iron oxide nano particles and this is used in dye degradation applications. Silver was blended with those nano particles for antibacterial activity. The UV results of iron oxide found to be $390 \mathrm{~nm}$, and the particle size of the iron nano composites were 50 to $120 \mathrm{~nm}$. The elemental compositions of the nano materials showed the presence of iron oxide and activated charcoal. Photo catalytic degradation of organic dye methylene blue by nano composite was performed. Microbes were collected from the waste water. Antibacterial properties of the nano composites were analysed by colony counting method.
\end{abstract}

Volume 2 Issue 5 - 2018

\author{
Subha V,' Divya K, ${ }^{2}$ Gayathri S, ${ }^{2}$ Jagan Mohan \\ E, ${ }^{2}$ Keerthanaa N, ${ }^{2}$ Vinitha $M,{ }^{2}$ Kirubanandan \\ $\mathrm{S}^{2}{ }^{2}$ Renganathan $\mathrm{S}^{2}$ \\ 'National Centre for Nano Science and Nanotechnology, \\ University of Madras, India \\ ${ }^{2}$ Department of Biotechnology, Anna University, India
}

Correspondence: Subha V, National Centre for Nano Science and Nanotechnology, University of Madras, India, Email mannargudisubha@gmail.com

Received: August 30, 2018 | Published: September 17, 2018

Keywords: dye degradation, nano-composite, iron oxide, silver, charcoal, anti-bacterial, waste water treatment

\section{Introduction}

Water is the most important and essential component on the earth but water quality of our water resources is deteriorating continuously due to human activities. Thousands of organic, inorganic, and biological pollutants have been reported as water contaminants. ${ }^{\text {'S }}$ Some of them have serious side effects and toxicities with a few being lethal and carcinogenic. These pollutants are very dangerous for all of us, aquatic conditions, and the ecosystem of the earth as a whole. ${ }^{2}$ Boiling, filtration, distillation, chlorination are the four common methods to treat waster. But for industry effluent water, water treatment is done based on pollutants present in it, commonly adsorption, membrane separation, activated sludge process etc., are used. Among many chemicals in industrial waste water, dyes are considered as important pollutants. Dyes can remain in the environment for an extended period of time, because of high thermal and photostability. Many dyes and their breakdown products are carcinogenic, mutagenic and toxic to life. Dyes increases BOD of effluent thereby affecting aquatic life. They are not readily degradable and are typically not removed from water by waste water treatment system and conventional techniques like adsorption, ultra filtration, chemicals, and electro chemical methods. Among many organic pollutants, methylene blue is one of the pollutants found in industrial effluent which affects on aesthetics of environment.

"Nano" is derived from the Greek word for "dwarf". This technology would certainly help the human being, our environment as well as industry too as it has shown amazing results in every fields. One among them is application of nano materials to detect, prevent and remove pollutants, ${ }^{3}$ or using nanotechnology to design eco friendly products. ${ }^{4}$ It has the potential to improve the life of people in general and especially of those with severe health problems ${ }^{5,6}$ Due to their unique active surface area, nano materials can offer a wide range of applications such as catalytic membranes, nano sorbents, bioactive nano particles and metal nano particles such as iron, silver, titanium oxides and many others. ${ }^{7}$ Nano materials are typically defined as materials smaller than $100 \mathrm{~nm}$ in at least one dimension. At this scale, materials often possess novel size-dependent properties different from their large counterparts, many of which have been explored for applications in water and wastewater treatment. ${ }^{8}$ Recently, photo catalytic reactions induced by illumination of semiconductors in suspension have been shown to be one of the most promising processes for the waste water treatment. Nano sized semiconductors such as $\mathrm{Fe}_{3} \mathrm{O}_{4}$ are often used as catalytic agents because of their high stability, low cost, high efficiency, no toxicity and reusability. Heavy metal contamination in water is of great concern because of its toxic effect on plants, animals and human beings, and its tendency for bioaccumulation even at relatively low concentration. ${ }^{9} \mathrm{Fe}_{3} \mathrm{O}_{4}$ is one of the magnetic nano particles (NP) which have been synthesized by energy milling, ultrasonic impregnation and using Tridax procumbens leaf extract. But co precipitation is very common method with yield around $96 \%$ to $99.9 \%$. It can be used in waste water treatment to adsorb heavy metals. ${ }^{10}$ After adsorption, $\mathrm{Fe}_{3} \mathrm{O}_{4}$ NPs can be collected and separated from the medium by a simple magnetic process. Thus, it is efficient, economic, scalable and non-toxic. It has been known that silver has antimicrobial activities for bacteria, fungi, and virus since ancient times. ${ }^{11}$ Compared with other metals, silver exhibits higher toxicity to microorganisms while it exhibits lower toxicity to mammalian cells. The toxic effects of silver on bacteria have been investigated for more than 60years. When Ag NPs mixed with waste water, it gets adhered to the microorganisms present and penetrates into the cells, forms complexes with bases contained in DNA that leads to cell death. ${ }^{12}$ They can also inactivate the enzymes produced by the cells. $\mathrm{Ag}^{+}$is a potent inhibitor of fungal DNAases. It is estimated that $1 \mathrm{~g}$ of Silver nano particle is sufficient to induce antibacterial activity to hundreds of square meters of substrate material. Ag NP's are synthesized using various methods such as biological, chemical, 
laser ablation etc. Among these the most common method is chemical reduction of silver salts by reducing agents like starch, sodium borohydride, sodium citrate, glucose etc. Adsorption is the most commonly used technique for the removal of dyes from industrial effluents. Activated charcoal (AC) is one of cheapest adsorbent which is easily accessible. It is made from variety of sources, but coconut shells are mostly preferred..$^{13}$ To make AC, charcoal has been processed to develop lots of internal spaces or "pores." These pores help activated charcoal "trap" chemicals. The porous AC has negative charge so that positively charged toxins, chemicals and gases gets adsorbed. In ancient times, $\mathrm{AC}$ was used to whiten teeth which adsorb plague and microscopic titbits that stain teeth. It's also used to reduce bloating and gas, lower cholesterol, treat bile flow problems safely during pregnancy, and even prevent hangovers. However AC has huge advantages in treating waste water. It adsorbs pesticides, chemicals, dyes etc but not viruses, bacteria. Incorporation of metal ion into lattice structure of $\mathrm{Fe}_{3} \mathrm{O}_{4}$ enhances the material properties such as surface sorption, photo-induced catalysis etc. Magnetic property of Fe NP's may be lost because they may get oxidised when exposed to $\mathrm{H}_{2} \mathrm{O}$ and air. To overcome this problem usually Fe NP's are protected by protection layer made of polymer, charcoal, silica or alumina. It has great efficiency for adsorptive reactive water treatment process. There are a number of potential biomedical applications for magnetic nano particles, which include the labeling and magnetic separation of biological materials, directed drug delivery, MRI contrast enhancement. ${ }^{14}$ Another application of magnetic nano particles is hyperthermia in cancer therapy. Super paramagnetic nano particles when exposed to an alternating magnetic field can be used to heat tumour cells to $41-45^{\circ} \mathrm{C}$, where tissue damage for normal tissue is reversible while the tumour cells are irreversibly damaged..$^{15}$

\section{Magnetic property}

The magnetic properties of iron oxides have been exploited in a broad range of applications including magnetic seals and inks, magnetic recording media, catalysts, and ferro fluids, as well as in contrast agents for magnetic resonance imaging and therapeutic agents for cancer treatment. ${ }^{16}$ These applications demand nano particle of specific sizes, shapes, surface characteristics, and magnetic properties. ${ }^{17}$ Magnetism is a unique physical property that independently helps in water purification by influencing the physical properties of contaminants in water. Adsorption procedure combined with magnetic separation has therefore been used extensively in water treatment. ${ }^{18}$ It is necessary to purify and recycle the industrial as well as the municipal waste water. From last decade the use of nano particles for water treatment have gained the special attention due to its property being highly profitable as an adsorbents and for using for filtration purpose. Further the type Magnetic Nano particles (MNPs) also possesses the properties like high surface area and being the super-magnetic in nature. Thus the MNPs are also being used for the removal of the toxic heavy metals/ elements like cations, natural organic matter, biological contaminants, and organic pollutants, Nitrates, Fluoride and Arsenic from the contaminated water.

\section{Dye degradation}

Organic dyes is one of the major groups of pollutants widely used in textile, plastic, medicine and many other industries, while the hazardous effects of organic dyes in waste water have been a major concern and now a major threat in the environment due to the substantial pollution problems caused by them. They are not readily degradable and are typically not removed from water by wastewater treatment systems and conventional methods like adsorption, ultra filtration, chemical and electrochemical methods. The superiority of photo catalytic degradation by nano particles in wastewater treatment is due to its advantages over the conventional methods, such as quick oxidation, no formation of polycyclic products and oxidation of pollutants. It is an effective and rapid technique in the removal of pollutants from wastewater.

\section{Anti-microbial potential of nano composite}

There is a demand for an alternative antibacterial treatment due to development of antibiotic resistance among bacteria. Ag NPs (Silver nano particles) exhibit bactericidal action against gram positive and gram negative bacteria. The cytoplasm membrane may shrink and become separated from the cell wall and the cell wall may be degraded. This may be the possible phenomena by which silver nano particle inhibit bacterial growth. The interaction between silver and constituents of bacterial membrane caused structural changes and damage to the membrane and intracellular metabolic activity which may be the cause or consequence of cell death. ${ }^{19}$ Current work is mainly concentrated on waste water treatment by iron nano composite. It is thus of necessity to control the harmful effects of contaminants and improve the human living environment. Contaminants persisting in wastewater include heavy metals, inorganic compounds, organic pollutants, and many other complex compounds. All of these contaminants releasing into the environment through wastewater are harmful to human beings and ecological environment. Consequently, the need for contaminants removal has become a must. The synthesis of $\mathrm{Fe}-\mathrm{AC}-\mathrm{Ag}$ nano composite which is capable of exhibiting antibacterial activity, adsorption and heavy metal reducing property was carried out by co precipitation method. The advantages of $\mathrm{Fe}_{3} \mathrm{O}_{4}$ NPs charcoal coated $\mathrm{Fe}_{3} \mathrm{O}_{4} \mathrm{NPs}, \mathrm{Fe}_{3} \mathrm{O}_{4}-\mathrm{AC}-\mathrm{Ag}$ nano composite was compared and found that the nano composite has tremendous benefits in the waste water purification.

\section{Methods and materials}

The samples were characterized using UV-visible spectrometer, XRD, SEM, and EDAX. Ferrous sulphate purchased from Himedia. Silver nitrate was purchased from Merck which was used for Ag NPs synthesis. Starch was used as a reducing agent which was purchased from Himedia. Sodium hydroxide was used as a precipitating agent purchased from SRL chem. De-mineralised (DM) water was used as a solvent.

\section{Synthesis of nano composite}

Using iron-oxide, activated charcoal and silver, the nano composite was synthesized by co-precipitation method. $10 \mathrm{~g}$ of $\mathrm{Fe}_{2} \mathrm{SO}_{4}$ was dissolved in $300 \mathrm{ml} \mathrm{DM}$ water. $0.8 \mathrm{~g}$ of $\mathrm{AC}$ was added uniformly by magnetic stirrer. $2 \mathrm{ml}$ of $0.1 \mathrm{M}$ silver nitrate was dissolved in $300 \mathrm{ml}$ of $0.15 \% \mathrm{w} / \mathrm{w}$ starch under constant stirring. These two solutions were blended and initial $\mathrm{pH}$ was checked using $\mathrm{pH}$ meter. $\mathrm{NaOH}$ was used to adjust the $\mathrm{pH}$ between 8 and 12. The whole mixture was stirred continuously for about $1 \mathrm{hr}$ at $50^{\circ} \mathrm{C}$. Synthesised nano composite was separated by centrifugation at $10000 \mathrm{rpm}$ for 15 minutes. Hot air oven was used for drying the nano composite. The dried nano composite was used for dye decolourisation and physical characterization such as surface morphology and appearance and structure via X-Ray diffraction. To compare the characteristics of nano composite, iron oxide nano particles and iron oxide-activated carbon nano particles were prepared by the following method.

\section{Synthesis of iron oxide nano particles}

Ferrous sulphate hexahydrate was used to synthesize iron oxide nano particles. $10 \mathrm{~g}$ of $\mathrm{Fe}_{2} \mathrm{SO}_{4}$ was mixed in $300 \mathrm{ml} \mathrm{DM}$ water under 
constant stirring using magnetic stirrer. After 5minutes, $2 \mathrm{M} \mathrm{NaOH}$ was added in drops till $\mathrm{pH}$ reaches 8 or above. It was stirred for $1 \mathrm{hr}$ at $50^{\circ} \mathrm{C}$ and kept it undisturbed to reach room temperature. The solution was subjected to centrifugation at $10000 \mathrm{rpm}$ for 15 minutes. The obtained paste was dried at $50^{\circ} \mathrm{C}$ in hot air oven for $10 \mathrm{mins}$. Then these composites were used for the analysis.

\section{Synthesis of iron oxide-ac nano particles}

To synthesize iron oxide-activated charcoal composites, ferrous sulphate hexahydrate and $\mathrm{AC}$ were dissolved in $300 \mathrm{ml} \mathrm{DM}$ water. For precipitation, $2 \mathrm{M} \mathrm{NaOH}$ was used and $\mathrm{pH} 8$ was adjusted. The whole solution was stirred using magnetic stirrer for $1 \mathrm{hr}$. Then it was centrifuged at $10000 \mathrm{rpm}$ for 15 minutes and dried.

\section{Characterisation}

UV-Vis spectrophotometer GENESYS10S was used to conform the formation of nano composite after diluting the solution in the range of $200-900 \mathrm{~nm}$.It is also used to characterize the surface plasma resonance properties of nano composite. FTIR is used to identify organic, polymeric and in some cases inorganic materials. FTIR analysis method uses infrared light to scan test samples and observe chemical property. FTIR is used to analyse functional groups present in the nano composite. The structural morphology, mean particle size of the nano composite could be characterized by scanning electron microscope (SEM).Crystalline nature of the nano composite was analysed by XRD analyser. The patterns were recorded in the region of a $2 \Theta$ range 10 to $90^{\circ}$. In a diffraction pattern, the intensity can be used to quantify the proportion of iron oxide formed in a mixture by comparing experimental peak and reference peak intensities. EDX analysis was done to reveal the presence of elemental composition in the sample.

\section{Dye degradation}

The methylene blue dye was prepared in $10 \mathrm{ppm}$ concentration for $500 \mathrm{ml}$. The optical density of the methylene blue dye at $610 \mathrm{~nm}$ is $0.316 .15 \mathrm{ml}$ dye was aliquoted in 5 test tubes i.e., $3 \mathrm{ml}$ in each test tube. Varying concentrations $(20,40,60,80$ and $100 \mathrm{mg})$ of the nano composite was added in each test tube. The optical density of the degraded dye was measured after $30 \mathrm{mins}$.

\section{Anti-bacterial activity}

\section{Agar well diffusion method}

Nano composite of different concentrations $(60,80,100 \mathrm{mg} / \mathrm{ml})$ was prepared. $20-30 \mathrm{ml}$ of agar was poured on petri plates of same size and allowed to solidify. Agar surface of each plate was swabbed by sterile cotton swab with bacillus strain. Agar plate was punched and $20 \mu 1$ of each sample was poured into the well. Plates were allowed to standby for $20 \mathrm{mins}$ and incubated at $37^{\circ} \mathrm{C}$ for $24 \mathrm{hrs}$.

\section{Waste water treatment}

The stagnant rain water sample was collected from the vicinity in a beaker. The $\mathrm{pH}$ of the sample was measured as 7.95 and the optical density at $600 \mathrm{~nm}$ read as $0.14 .20 \mathrm{mg}$ of the nano composite was packed in a tea bag and dipped inside $20 \mathrm{ml}$ of the isolated sample. After incubation time of 10minutes, the sample is again measured for $\mathrm{pH}$ and optical density. The efficiency of separation and reusability of the nano composite is tested.

\section{Result and discussion}

\section{UV-Vis spectrophotometer}

The synthesized nano particle was initially characterized by UVVis spectroscopy. In this method, the amount of light was absorbed and scattered by the sample in the range of 190 to $800 \mathrm{~nm}$. The UVanalysis was achieved by GENESYS10S UV-Vis spectrophotometer. The absorption spectrum of $\mathrm{Fe}-\mathrm{AC}-\mathrm{Ag}$ nano composite has been measured and compared with $\mathrm{Fe}_{3} \mathrm{O}_{4}$ and $\mathrm{Fe}_{3} \mathrm{O}_{4}-\mathrm{AC}$ nano particles. The maximum absorption peak for nano composite was observed at 600 $\mathrm{nm}$ which is broader than iron oxide and iron oxide- $\mathrm{AC}$ absorption peaks at $215 \mathrm{~nm}$. Figure 1 shows the absorption spectrum of nano composite and Figure 2 shows the absorption spectrum of iron oxide nano particle. The absorption of the metallic nano particles such as $\mathrm{Ag}, \mathrm{Fe}$ is due to the surface plasmon absorption. ${ }^{20}$

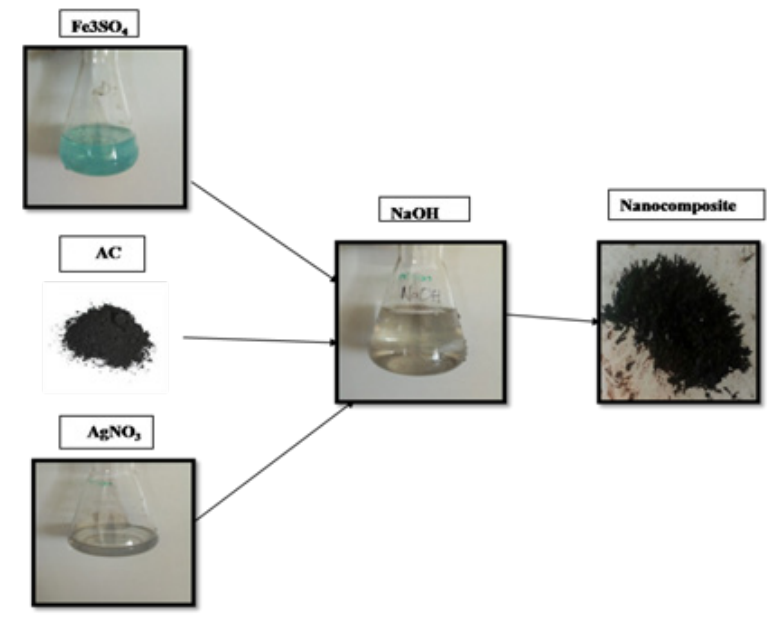

Figure I Process of nano composite synthesis using iron sulphate, activated charcoal, silver nitrate and $\mathrm{NaOH}$ for precipitation.

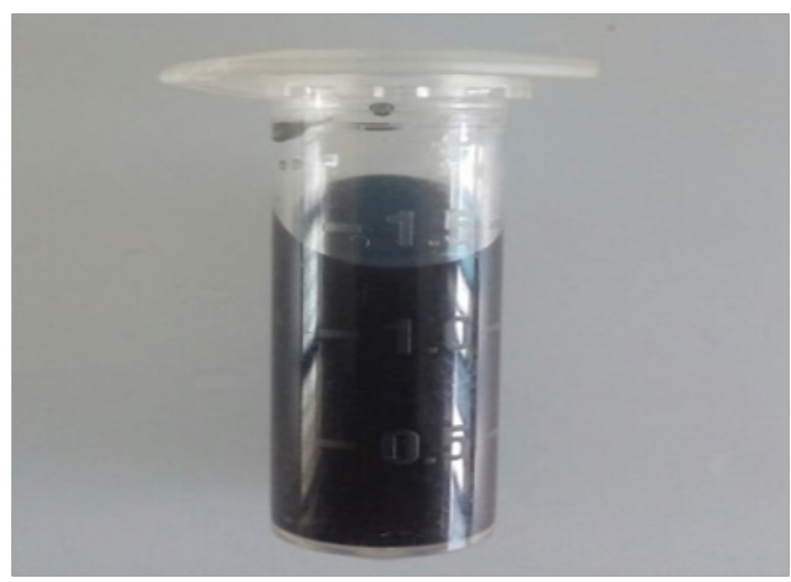

Figure 2 Nano composite was mixed in distilled water.

\section{Dye degradation}

The optimization of dye degradation property of the nanocomposite is carried out by photo catalytic degradation technique Figure 3, Figure 4. A 10ppm solution of methylene blue has been prepared and tested against different amount of nano particles. $3 \mathrm{ml}$ of the dye sample is taken in 5 different test tubes and are treated with different amount of nano particles such as 20, 40,60, 80 and 
$100 \mathrm{mg}$ respectively. The minimal optimum concentration of the nano-composite to degrade the dye (Methylene blue) was found to be $40 \mathrm{mg}$. The optical density of sample which has $40 \mathrm{mg}$ of nanocomposite measured 0.05 , while it was 0.316 , initially. This drastic colour change is due to photo catalytic degradation reaction of nanocomposite. Then the degraded dye molecules were absorbed by Activated charcoal from the water was clearly narrated by Figure 5, Figure 6. This is the unique step of this nano composites. This iron nano composties can be recyclable. After finding the optimum nano composite concentration, optical density of methylene blue dye was measured by varying time. A mix of $4 \mathrm{ml}$ dye sample and $40 \mathrm{mg}$ of nano-composite was prepared in a test tube and the initial optical density was found to be 0.316 . As the time proceeds, different readings were taken at 5, 10, 15, 20 and 25 seconds respectively. And the time period of 25 seconds was found to be effective, when the calorimeter read the lowest value of 0.018 optical density.

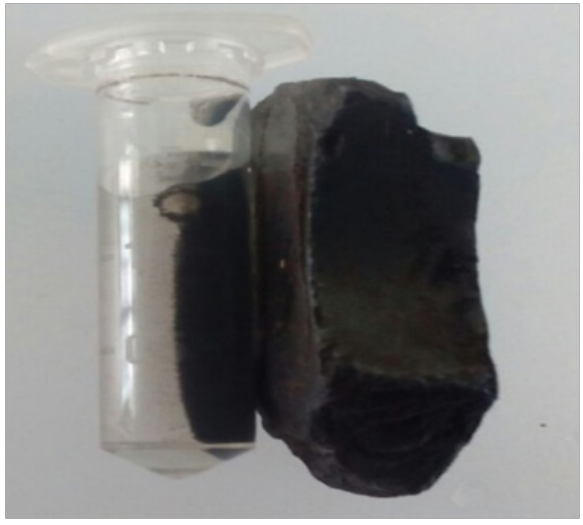

Figure 3 Nano composite was attracted towards magnet in solution.

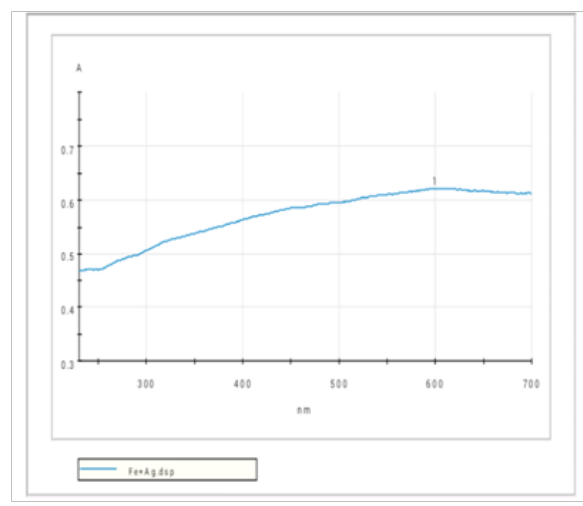

Figure 4 Absorption spectrum of nano composite.

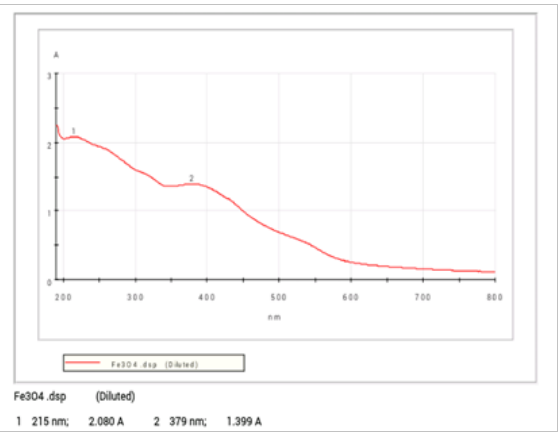

Figure 5 Absorption spectrum of iron oxide nano particle.

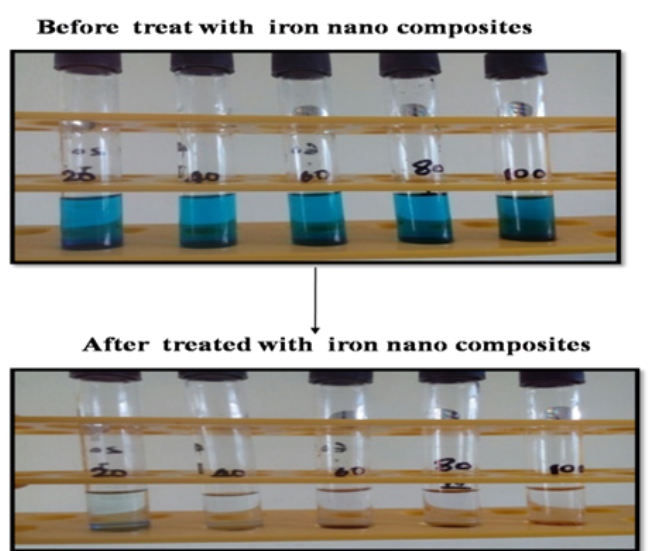

Figure 6 Methylene blue dye is degraded using various concentrations of nano composite.

\section{$\mathbf{X}$-ray diffraction (XRD)}

$\mathrm{XRD}$ is an effective technique to identify the phase and to confirm the crystal structure of the synthesized iron oxide nano particles. The X-Ray diffraction pattern of the iron oxide nano particles, nano composite, iron oxide-AC nano particles synthesized is shown in Figure 7-9 respectively. Figure 7 represents the $\mathrm{Fe}_{3} \mathrm{O}_{4}$ magnetic nano particles XRD pattern, the XRD peak $2 \theta$ values such as 30.29 , $35.69,57.2662 .9$ corresponds to (220), (311), (333), (440) hkl values respectively and the PCPDF reference pdf No is. 89-4319. From the XRD values one can conclude that the synthesized iron magnetic nano particles lattice structure is face centered and the crystalline nature of the particles found to be cubic which was clearly implied in SEM images. Figure 8 XRD peak represents the iron oxide and charcoal composites. The $2 \theta$ values such as $30.5,35.8,43.6,57.4$ and 63.0 corresponds to (220), (113), (404), (530) and (711) hkl values, in which the 43.6 theta value represent the presence of activated charcoal. From this XRD results the synthesized iron oxide and activated charcoal particle crystalline nature is face-centred and structure is cubic. Figure 9 XRD image represents the iron oxide, activated charcoal and silver nano composites, in which the XRD $2 \theta$ peaks values most of the XRD peaks denoting iron oxide peaks such as 30.4, 36.8,57.5 and 63.0, which showing the crystalline nature of iron oxide as it was mentioned in above Figure 7 . The activated charcoal $2 \theta$ peak value 43.7 is corresponds to (111) hkl value and the crystalline shape of the activated charcoal is face-centred, cubic structure. In the same Figure 9 silver particles XRD peak was dominated by iron and charcoal peaks because silver particles impregnated in side of charcoal, hence the silver particles peak was absent in this iron nano composites.

\section{SEM analysis}

Scanning electron microscope is a device use to find out the outer surface details of a particle. It uses high power electron beams on the surface of the atoms to provide discrete image of topography of the particle with respect to proper scale. SEM analysis of nano composite is carried out using. The processed SEM images show the structural appearance of the nano composite molecules. The smaller molecules depict the aggregates of unstable molecules whereas the larger ones represent the molecules intact. The nano composite appears to have a three dimensional shape. Figure10 image shows the iron oxide nano particles SEM image, the size of the iron oxide nano particles surface morphology is spherical in shape and the size of the particles start from start from 60 to $90 \mathrm{~nm}$ and average particle size is $80 \mathrm{~nm}$. The Iron oxide and $\mathrm{AC}$ composition shown in Figure11 in which 
the surface morphology of the iron particles and activated charcoals shown as coarser. Activated charcoal adhered on the surface of the iron nano particles. The particles size range start from 90 to $120 \mathrm{~nm}$. The average particle size would be $90 \mathrm{~nm}$. Then the iron oxide, AC and silver nano composites shown in Figure12, Figure 13. silver particles impregnated inside of the activated charcoal so that the EDAX peaks was dominated by iron and carbon particles and this results further supported by XRD peaks values. The average particle size is $80 \mathrm{~nm}$.
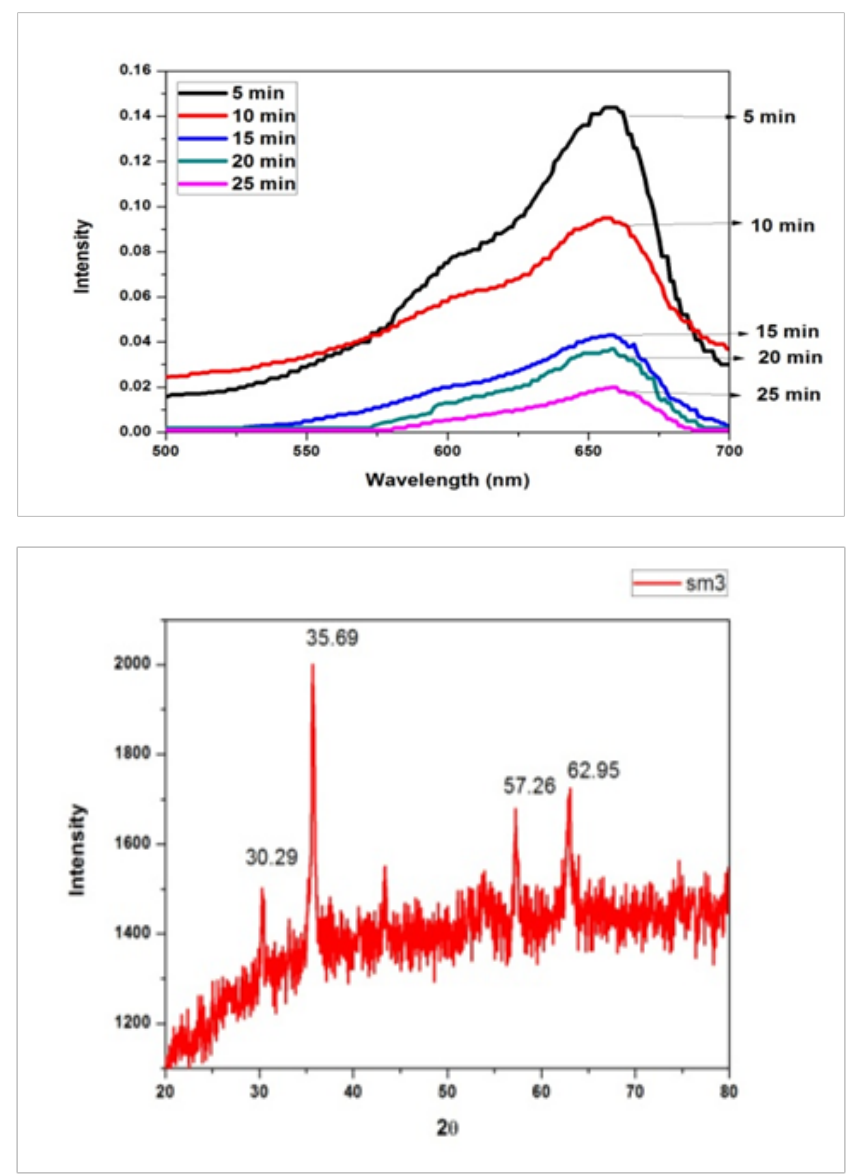

Figure 7 XRD pattern of iron oxide nano particle.

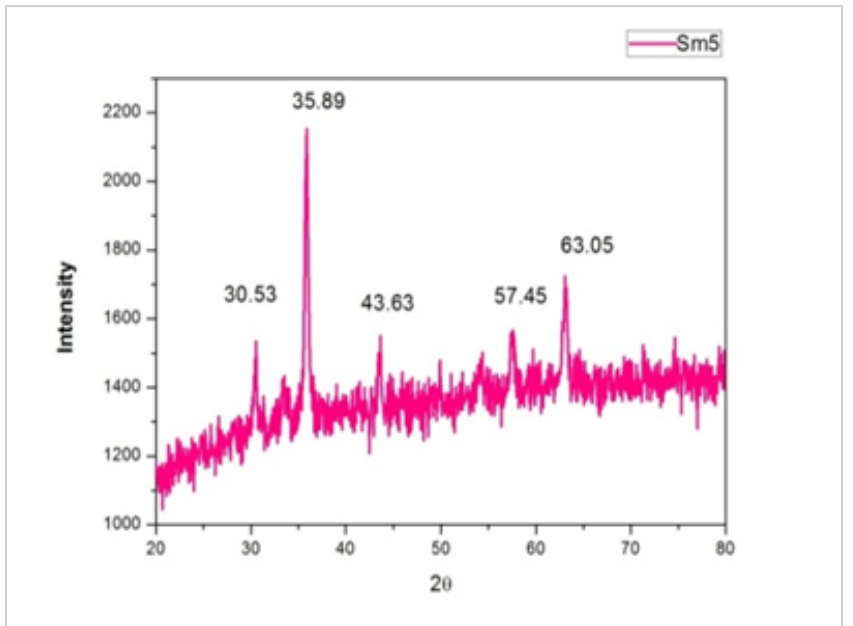

Figure 8 XRD pattern of iron oxide and activated charcoal nano composite.

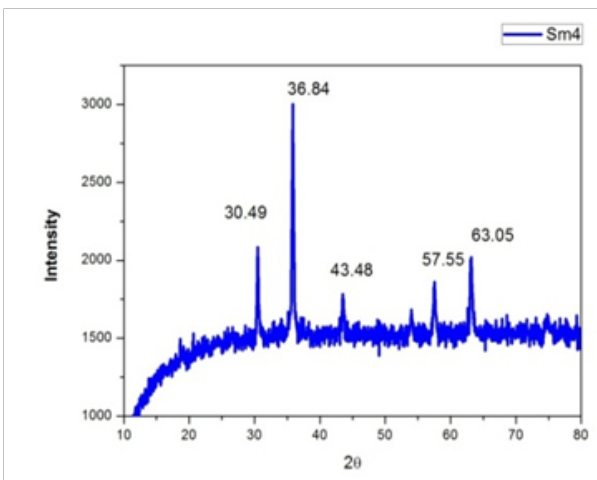

Figure 9 XRD pattern of iron oxide $-\mathrm{Ag}-\mathrm{AC}$ nano composites.

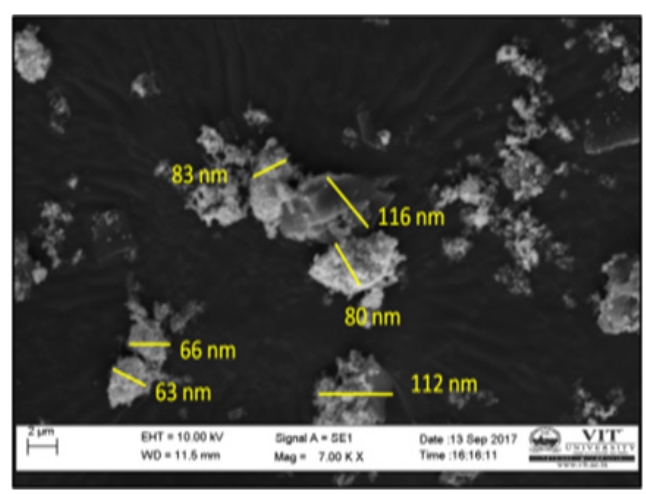

Figure 10 SEM analysis of iron oxide nano particle.

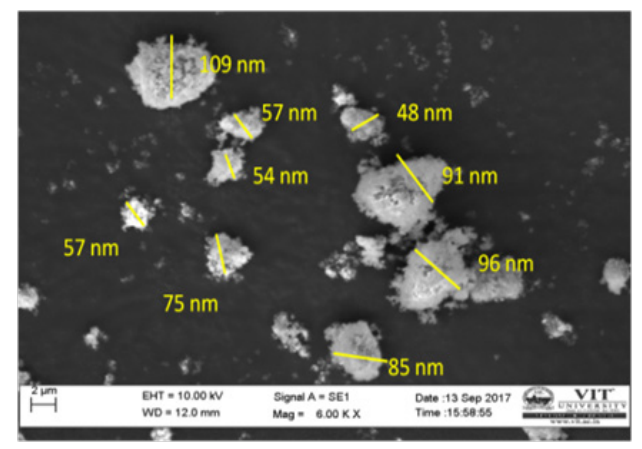

Figure II SEM analysis of nano composite.

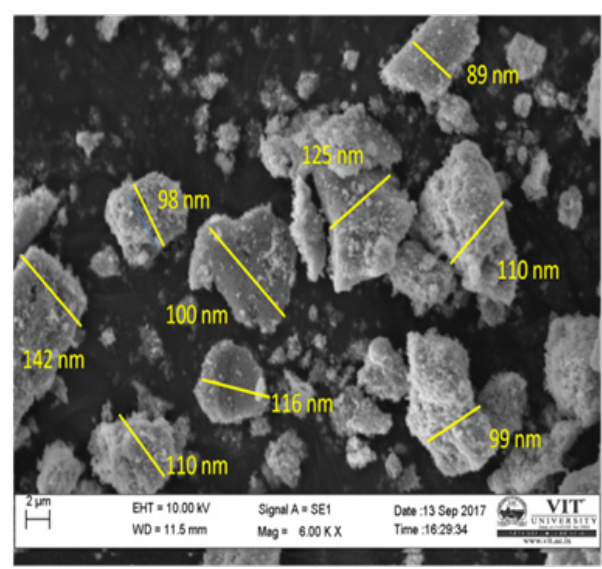

Figure 12 SEM analysis of iron oxide-AC nano particle. 


\section{Energy dispersive $\mathbf{x}$-ray analysis (EDX)}

EDX is an analytical technique used for the elemental analysis or chemical characterization of a sample. Figure 13 shows the SEM-EDX image and graph of iron oxide nano particle. The peak in the graph confirms the presence of iron. Figure 14 shows the SEM-EDX image and graph of iron oxide and AC nano particle. This graph has 5 peaks for iron, oxygen, carbon, sodium, sulphur. Presence of sodium and sulphur peaks was due to $\mathrm{NaOH}$ and ferrous sulphate used for the synthesis. Presence of activated charcoal confirms that activated charcoal was coated on iron oxide nano particle. Figure 15 shows the SEM-EDX image and graph of nano composite. It has 3 peaks for iron, oxygen and carbon and this confirms that activated charcoal was coated on iron oxide nano particle.

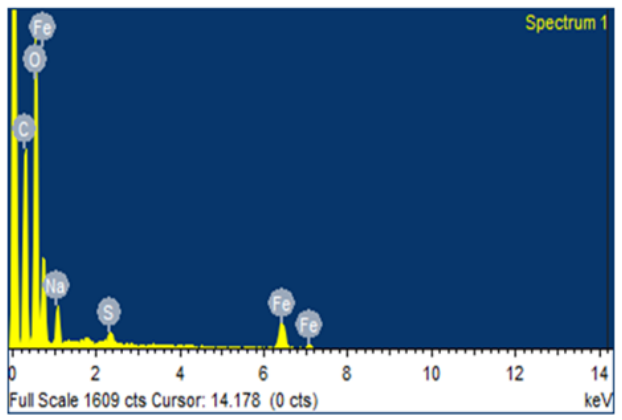

Figure I 3 SEM-EDX image of iron oxide nano particle.

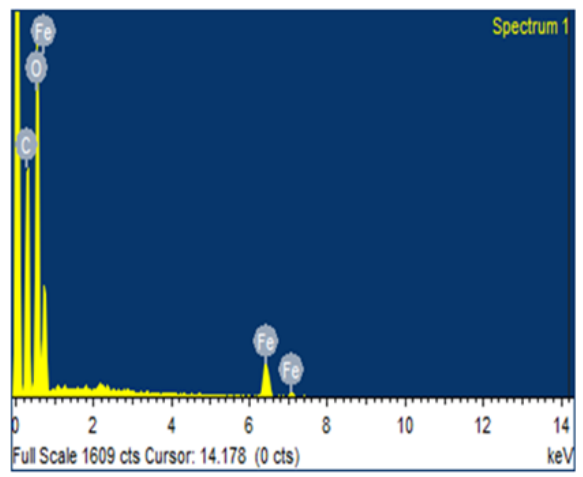

Figure I 4 SEM-EDX image of iron oxide and $\mathrm{Ag}-\mathrm{AC}$ nano composites.

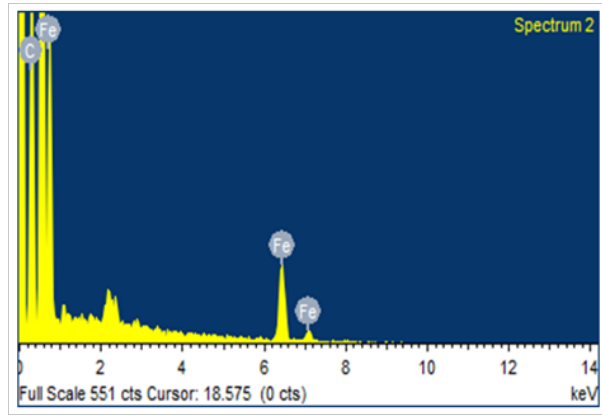

Figure I 5 SEM-EDX graph of iron oxide and AC nano particle.

\section{Anti-microbial activity}

Anti-microbial properties of nano particles can be achieved by the following methods such as diffusion (Kirby-Bauer and Stokes), dilution (minimal inhibitory concentration), diffusion and dilution (E test), Figure 16 shows the zone of inhibition $(3 \mathrm{~mm})$ against the bacillus sp. with different concentration of nano composite such as 60,80 and $100 \mathrm{mg} / \mathrm{ml}$. Chloramphenicol was used as positive control. Maximum zone of inhibition was absorbed at $80 \mathrm{mg} / \mathrm{ml}$. This antibacterial activity of nano composite is due to presence of silver. Silver ion is a highly reactive moiety and avidly binds to tissue proteins, causing structural changes in bacterial cell walls and intracellular and nuclear membranes. These lead to cellular distortion and loss of viability. Silver binds to and denatures bacterial DNA and RNA, thereby inhibiting replication. Iron oxide particles also possesses some amount of bactericidal action.

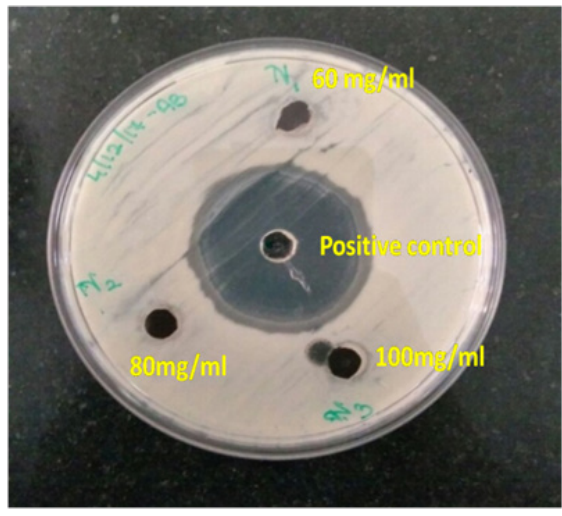

Figure I 6 Antimicrobial activity of various concentrations of nano composite.

\section{Waste water treatment}

The $\mathrm{pH}$ and optical density of the waste water after treating with the nano composite was measured as 7.67 and 0.01 respectively. With respect to the fresh waste water collected, the waste water after treatment has relatively low $\mathrm{pH}$ value and a drastic decrease in the optical density. This evidently proves the adsorbent property of the composite. Due to magnetic property of iron oxide easy separation of the nano composite from the solution is possible. The reuse of the previously used nano composite is found to yield $50 \%$ efficiency as that of the new one. $\mathrm{pH}$ and optical density after reuse is measured as 7.93 and 0.05 respectively Figure 17, Figure 18. The nano composite is more efficient in the decolorization of methylene blue dye and reaching $100 \%$ decolorized in 30minutes. The dye degradation performance of nano composite also depends on the structure and characterises of dyes present in the water and properties of nano composite and its surface. The Figure 19 concludes the kinetics of the dye decolourization with nano composite and this kinetic fit concludes the first order kinetics of dye degradation.

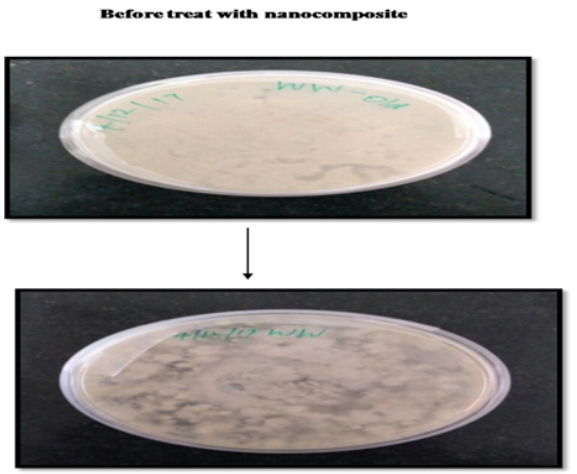

After treat with nanocomposite

Figure 17 Antibacterial activity of nano composite was checked in waste water. 


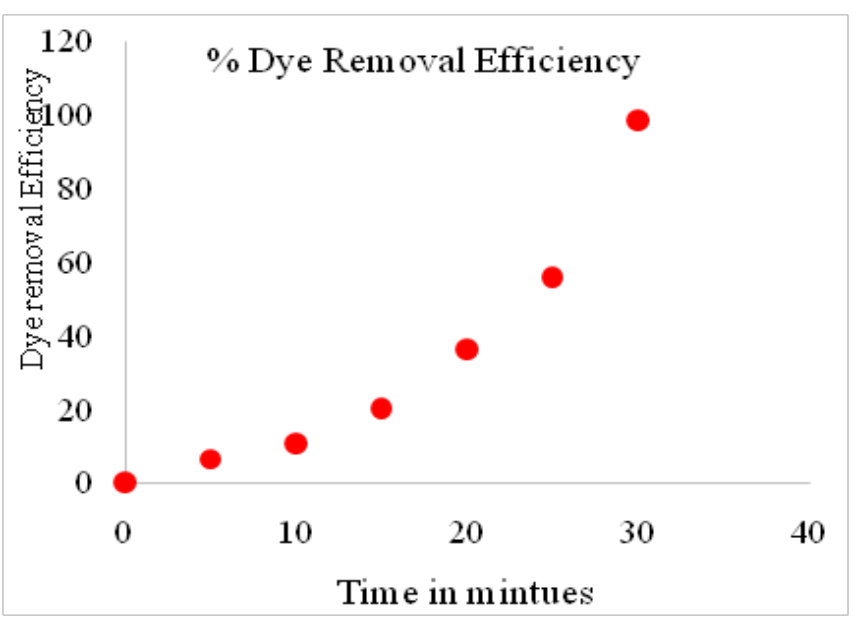

Figure I 8 Efficacy of decolourisation of dyed water with nano composite.

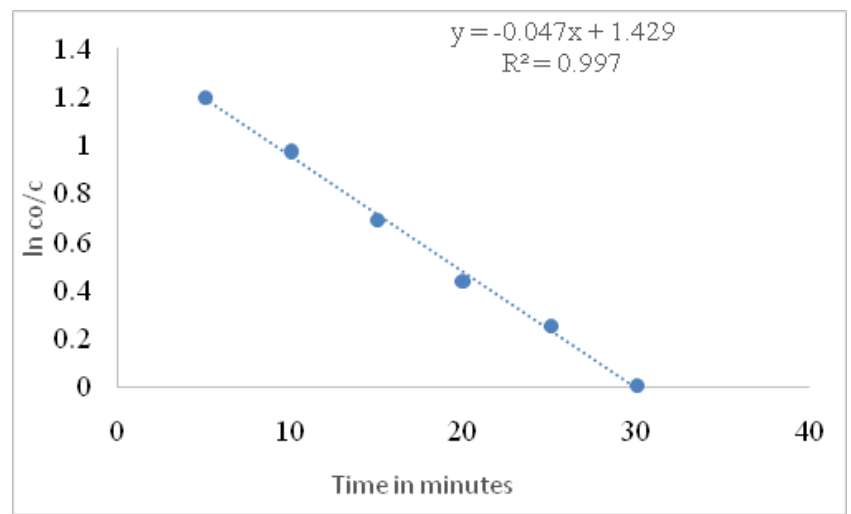

Figure 19 Kinetics of dye decolourization with nano composite.

\section{Conclusion}

The present investigation on co precipitation method shows that silver component of the nano composite can be readily reduced from silver nitrate by using starch. Antibacterial activity was observed due to presence of silver and iron oxide nano particle. AgNPs is capable of adhering to microbial cells and penetrate inside the cell leading to generation of ROS (reactive oxygen species) and free radicals. These leads to modulation of microbial signal transduction pathway. This is the most prominent mode of antibacterial action. The synthesised nano composite exhibited excellent photo catalytic activity against methylene blue dye. It is due to adsorption property of charcoal and heavy metal reducing property of iron oxide. Because of these properties synthesised nano composite can be used in degrading the dye and can be used in water purification systems and dye effluent treatment.

\section{Acknowledgements}

None.

\section{Conflict of interests}

The author declares that there is no conflict of interest.

\section{References}

1. Laws EA. Aquatic Pollution: An Introductory Text. 3rd ed. John Wiley \& Sons: New York; 2000.
2. Duruibe JO, Ogwuegbu MOC, Egwurugwu JN. Heavy metal pollution and human biotoxic effects. International Journal of Physical Sciences. 2007;2 (5):112-118.

3. Pankaj Ramnani Nuvia M, Saucedo Ashok Mulchandani. Carbon nanomaterial-based electrochemical biosensors for label-free sensing of environmental pollutants. Chemosphere. 2016;143:85-98.

4. Arun G, Ingale, Chaudhari AN. Biogenic Synthesis of Nano particles and Potential Applications: An Eco Friendly Approach. J Nanomed Nanotechol; 2013.

5. Mark E Davis, Zhuo (Georgia) Chen, Dong M Shin. Nano particle therapeutics: an emerging treatment modality for cancer. Nanoscience and Technology. 2009;239-250.

6. Franck Furno Kelly S, Morley Ben Wong Barry L, Sharp Polly L. et al. Silver nano particles and polymeric medical devices: a new approach to prevention of infection? Journal of Antimicrobial Chemotherapy. 2004;54(6):1019-1024.

7. Karishma K, Chorawalaa, Mehali J Mehtab. Applications of Nanotechnology in Wastewater Treatment. International Journal of Innovative and Emerging Research in Engineering. 2015;2(1):1-26.

8. Xiaolei Qu, Pedro JJ Alvarez, Qilin L. Applications of nanotechnology in water and wastewater treatment. water research. 2013;47(12):3931-3946.

9. Piao Xu, Guang Ming Zeng, Dan Lian Huang, et al. Use of iron oxide nano materials in wastewater treatment. Science of The Total Environment. 2012;424:1-10.

10. Poedji Loekitowati Hariani, Muhammad Faizal, Ridwan Marsi, et al. Synthesis and Properties of $\mathrm{Fe}_{3} \mathrm{O}_{4}$ ano particles by $\mathrm{Co}$-precipitation Method to Removal Procion Dye. International Journal of Environmental Science and Development. 2013;4(3):336-340.

11. Baker C, Pradhan A, Pakstis L, et al. Synthesis and Antibacterial Properties of Silver Nano particles. Journal of Nanoscience and Nanotechnology. 2005;5(2):244-249.

12. Soo-Hwan, Hyeong-Seon Lee, Deok-Seon Ryu, et al. Antibacterial Activity of Silver-nano particles Against Staphylococcus aureus and Escherichia coli, Korean. J Microbiol Biotechnol. 2011;39(1):77-85.

13. Emmanuel E, Egbon,Victoria O, Idode, et al. Treatment of Saloon Waste Water Using Activated Carbon. Chemical and Process Engineering Research. 2013;17.

14. Dale L. Huber Synthesis, Properties, and Applications of Iron Nano particles, small. USA. 2005;1(5):482-501.

15. Teja AS, Koh PY. Progress in Crystal Growth and Characterization of Materials. USA. 2009;55:22-45.

16. Luiz CA, Oliveira Rachel, Rios VRA, et al. Activated carbon/iron oxide magnetic composites for the adsorption of contaminants in water, Carbon. USA. 2002;40(12): 2177-2183.

17. Teja AS, Koh PY. Progress in Crystal Growth and Characterization of Materials. USA. 2009;55: 22-45.

18. Ming Hua, Shujuan Zhang, Bingcai Pan, et al. Heavy metal removal from water/wastewater by nano sized metal oxides. Journal of Hazardous Materials. 2012;211-212:317-331.

19. Jose Ruben Morones, Jose Luis Elechiguerra, Alejandra Camacho, et al. The bactericidal effect of silver nano particles. Institute of physics. 2005;2346-2353.

20. Garcia MA. Surface plasmons in metallic nano particles: fundamentals and applications. J Phys D:Appl Phys. 2011;45:389501. 